\title{
EDITORIAL
}

\section{CINCO AÑOS DE}

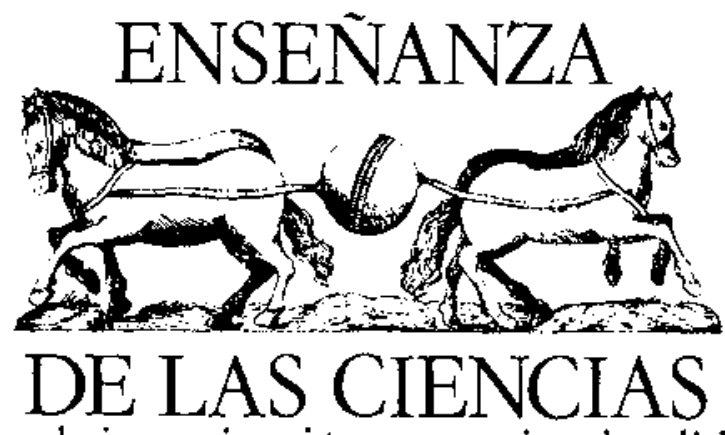

Revista de investigación y experiencias didacticas

En 1983, un acuerdo interuniversitario de la Universitat Autònoma de Barcelona y la Universitat de València, hacia posible la aparición de Enseñanza de las Ciencias. La idea de una revista centrada en la investigación didáctica podía parecer descabellada en un país sin apenas tradición en este campo. De hecho, en aquella fecha, las revistas internacionales especificas tenian poca difusión entre nosotros. Pero Enseñanza de las Ciencias no sólo pretendía facilitar la publicación de la escasa investigación que empezaba a realizarse, sino, fundamen* talmente, impulsar dicha investigación; de ahú el papel otorgado, desde el primer momento, a secciones como «Reseñas bibliográficas», "Selecciones bibliográficas temáticas», "Presen* tación de revistas", "Grupos de trabajo», "Debates», etc., etc., a través de las cuales se ha ido of reciendo una panorámica de la investigación internacional y se han facilitado los contactos entre distintos grupos.

Hoy, una perspectiva de cinco años permite constatar que el esfuerzo ha merecido la pena: con cerca de 2.500 subscriptores, Enseñanza de las Ciencias se ha convertido en vehículo y punto de referencia obligado para la investigación sobre didáctica de las ciencias, en nuestro país y empieza a serlo en América Latina. Más aún, en sus páginas han ido apareciendo trabajos originales de algunos de los autores con más prestigio internacional. El Indice Analítico de estos cinco años -que distribuimos con este número- proporciona algunos datos objetivos de indudable interés sobre el número de autores que han colaborado hasta el momen* to (varios centenares), su campo de trabajo, etc. Junto a ello, la organización de dos Congresos Internacionales - - en 1985 y 1987 — ha permitido recoger, en sendos números extra, cerca de 300 comunicaciones.

Todos estos resultados responden, obviamente, a un amplio esfuerzo colectivo del que todos cuantos hemos colaborado en esta empresa podemos sentirnos satisfechos. Pero una mirada retrospectiva no tiene sentido si se limita a resaltar los aspectos positivos del trabajo ya realizado: ha de ser ocasion, sobre todo, de una revisión crítica que ayude al necesario perfeccionamiento. Por ello, desde este Editorial, solicitamos de todos los colaboradores y lectores el envio de las críticas o sugerencias susceptibles de convertir la revista en un instrumento más útil. Iniciaremos aś, a partir del próximo volumen, una segunda etapa de Enseñanza de las Ciencias, introduciendo los cambios que esta reflexión crítica colectiva recomiende. Esperamos, pues, vuestra colaboración. 